\title{
THEORY AND PERFORMANCE OF A SLURRY FLOW IN FORM OF A FILM IN THE 6ERM-35/315 SEPARATOR WITH A HIGH-GRADIENT MAGNETIC FIELD
}

\author{
A.M. TURKENICH \\ The Institute of Geotechnical Mechanics of the National Academy of \\ Sciences of the Ukraine, Dnepropetrovsk, Ukraine
}

(Received March 19, 1996, accepted June 5, 1996)

\begin{abstract}
$\underline{\text { Abstract }}$
The physical foundations and theoretical determination of conditions for formation of a slurry flow in form of a film along ferromagnetic plates of a rotary high-gradient magnetic separator are described. It is shown that this new hydrodynamics allows to increase not only the reliability of the separator thanks to the increase of the width of gaps between the plates, but also to improve its metallurgical efficiency.
\end{abstract}

\section{INTRODUCTION}

One of the main principles of high-gradient magnetic separators which are used for beneficiation of fine weakly magnetic ores, is the slurry filtration through narrow gaps between ferromagnetic bodies. This principle presents a contradiction between a necessity to decrease the width of a gap in order to increase magnetic particle recovery and a necessity to increase the width of a gap in order to decrease the probability of the clogging of a gap.

It is impossible to settle this contradiction within the framework of the principle of slurry filtration. The most reliable among such machines is Jones rotary separator where ferromagnetic plates with vertical ridges and grooves are used. Vertical gaps 
between such plates are the least subject to clogging. Therefore, we used this matrix for further improvement [1]. Results of of these investigations and their industrial realisation have been published elsewhere [2, 3]. However, physical fundamentals and theoretical description, as well as a more precise confirmation of technological advantages has not been published as yet. The aim of this paper is to rectify this situation.

\section{PHYSICAL FUNDAMENTALS AND THEORY OF A NEW SOLUTION}

The above mentioned contradiction of rotary magnetic separators has been overcome through a formation of new hydrodynamics. The essence of this hydrodynamics is that a slurry flows in the form of a film along the walls of ferromagnetic plates [1]. In this case, the slurry is absent in the centre of the gap between the plates. As a result of this fact, it is possible to increase the width of the gap to 4 or $5 \mathrm{~mm}$, the width that can eliminate blockage.

In spite of of such a large width of the gap, the distance of magnetic particles from the surface of the plates does not increase since the thickness of the film can have any value that may be required. As a result, it is possible to treat fine minerals without a necessity to reduce the width of the gap.

In order to form the film flow of a slurry, a new type of ferromagnetic plates has been developed [4]. These plates have grooves inclined on opposite sides of the gap in different directions, as is shown in Fig. 1. The grooves can have rectangular, triangular or other forms.

If a slurry stream entering a gap, touches both sides of this gap, the slurry ;eaves the stream and enters the grooves. Further, the slurry flows along these grooves and is supported by surface tension. An open surface of the slurry is limited by a meniscus with a stable profile. Schematic diagram for evaluation of parameters of the slurry flow along the grooves of a triangular cross-section is shown in Fig. 2.

Loytsansky [5] showed that the system Stokes equations of motion and the equation of continuity of vertical flow with open surface are transformed into a single differential equation: 


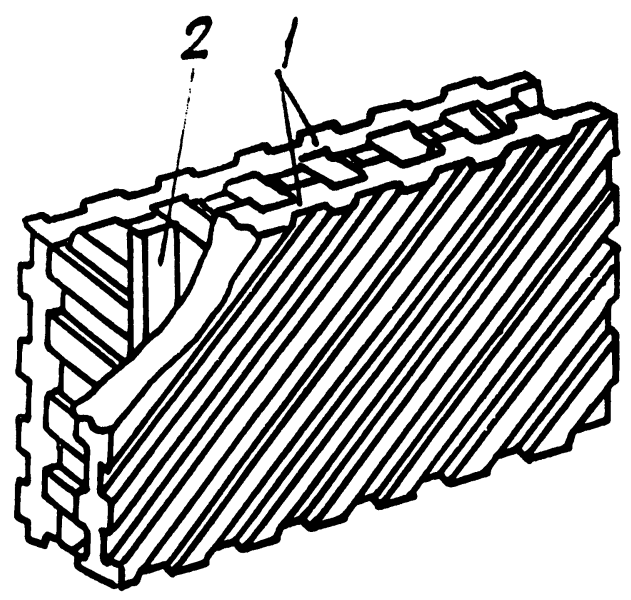

Fig. 1 Ferromagnetic plates with inclined ridges and grooves.

(1) plates, (2) spacers

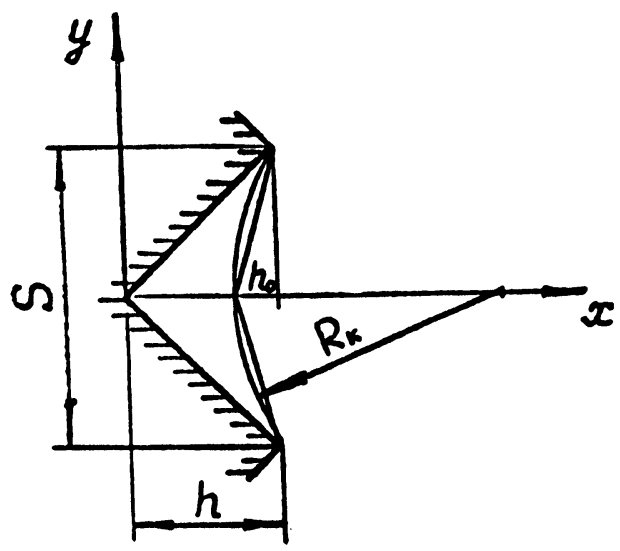

Fig. 2 Schematic diagram for evaluation of the slurry flow in a groove of triangular cross-section.

$\frac{\mathrm{d}^{2} \mathrm{~V}}{\mathrm{dx}^{2}}+\frac{\mathrm{d}^{2} \mathrm{~V}}{\mathrm{dy}^{2}}=\frac{\rho \mathrm{g}}{\mu}$ 
where $V$ is the local velocity of the slurry flow, $x$ and $y$ are the coordinates of the cross section of the flow, $\rho$ and $\mu$ are the density and kinematic viscosity of the slurry, respectively, and $g$ is the acceleration of gravity.

Boundary conditions of the solution of this equation are the equality to zero of the value of the slurry velocity on the walls of the grooves, and of its gradient along the normal to the slurry surface.

Having resolved eq. (1) and integrated this solution over all the area of the cross-section of the flow, formulae have been obtained [6] for calculation of the volumetric throughput of the slurry flow along the grooves:

$$
\mathrm{Q}=\frac{\mathrm{s}^{2} \rho \mathrm{g}\left(\mathrm{h}-\mathrm{h}_{\mathrm{o}}\right) \sin \beta}{48 \mathrm{~h}_{\mathrm{o}} \mu}
$$

and the mean flow velocity:

$$
\mathrm{V}=\frac{\mathrm{s} \rho \mathrm{g}\left(\mathrm{h}-\mathrm{h}_{\mathrm{o}}\right)^{2} \sin \beta}{24 \mathrm{~h}_{\mathrm{o}} \mu}
$$

where $s$ and $h$ are the step and the depth of the grooves, respectively, $h_{0}$ is the sag of the meniscus, $\beta$ is the angle between the groove and the horizontal line. $h_{0}$ can be expressed as:

$$
h_{0}=R_{k}+\left(R_{k}^{2}-\frac{s^{2}}{4}\right)^{\frac{1}{2}}
$$

where $R_{\mathrm{k}}$ is the radius of the meniscus with a stable form and is given by:

$$
\mathrm{R}_{\mathrm{k}}=\mathrm{K}\left(\frac{\sigma}{\rho \mathrm{g}}\right)^{\frac{1}{2}}
$$

where $\sigma$ is the surface tension of the slurry $\left(72 \times 10^{-3} \mathrm{~kg} / \mathrm{s}\right)$ and $K=0.5$ to 1.0 .

The largest specific volumetric throughput of the slurry, i.e. throughput per unit horizontal length of the gap, when the slurry flow is in the form of a film, is defined by equation: 


$$
\mathrm{q}=\frac{2 \mathrm{Q} \sin \beta}{\mathrm{s}}
$$

In this case the depth of penetration of the slurry stream into the gap between plates is:

$$
\mathrm{H}=\mathrm{Atan} \beta
$$

where $A$ is the distance between spacers.

The more specific output in comparison with that defined by eq. (6), the more volume of the slurry moves in the form of a stream occupying the entire width of the gap without dividing into films, the smaller is the recovery of magnetic particles.

\section{TECHNOLOGICAL ADVANTAGE OF THE FILM FLOW OF THE SLURRY}

Plates with inclined grooves were used a matrix in the rotary 6ERM-35/315 separator with high gradient magnetic field [2]. The separator has one rotor and two magnetic circuits. The separator has two independent branches of slurry movement through three levels of separation. The upper level of separation is performed at the field intensity of $0.3 \mathrm{~T}$ between the plates and is used for the recovery of particles with high magnetic susceptibility. The yield of the magnetic fraction in this level of separation is about 20 to $30 \%$ in a case of oxidised iron ore.

The remaining magnetic particles passed into the lower levels of separation. Both of these levels have new magnetic plates with a gap of $4 \mathrm{~mm}$, as described above, and the magnetic field intensity is $1.15 \mathrm{~T}$. The plates in these levels have triangular grooves with $\beta=65^{\circ}$ and $s=3.5 \mathrm{~mm}$. The height of the plates is 220 $\mathrm{mm}$. Every level of separation has 27 matrices with 15 gaps between the plates. The horizontal length of a gap is $280 \mathrm{~mm}$. The distance between the spacers is 75 $\mathrm{mm}$. A slurry is fed into four matrices simultaneously through one feeder.

Treatment of iron ore in the beneficiation plant in Krivoy Rog is carried out in two stages of separation. In the first stage the output from one branch of the slurry 
movement inside the separator is $50 \mathrm{t} / \mathrm{h}$ of ore, or $75 \mathrm{~m}^{3} / \mathrm{h}$ of slurry at the density of $40 \%$ of solids.

Table 1 shows the specific volumetric throughput of the separator 6ERM-35/315 in both stages of beneficiation and the results of calculation by eq. (6) of the largest specific volumetric throughput, when the film flow is used. Experimentally determined throughput is also given. The slurry viscosity was $\mu=2 \times 10^{-3} \mathrm{~m}^{2} / \mathrm{s}$ and density $\rho=1.3 \times 10^{3} \mathrm{~kg} / \mathrm{m}^{3}$.

Table 1 Specific volumetric throughput

\begin{tabular}{|c|c|c|c||}
\hline \multirow{2}{*}{$\begin{array}{c}\text { Stage of } \\
\text { beneficiation }\end{array}$} & \multirow{2}{*}{$\begin{array}{c}\text { Specitic } \\
\text { throughput of } \\
\text { 6ERM-35/135 }\end{array}$} & $\begin{array}{c}\text { Maximum specific } \\
\text { throughput with slurry film } \\
\text { flow }\end{array}$ \\
\cline { 3 - 4 } & 1.14 & 0.51 & 0.63 \\
\hline First & 0.57 & 0.51 & 0.63 \\
\hline Second & Calculated & Experimental \\
\hline
\end{tabular}

As can be seen from Table 1, specific throughput of the first stage of beneficiation is two times higher than it is permissible for creation of the slurry film flow. As the yield of the first stage magnetic product was about $50 \%$, the volumetric throughput of a slurry of the same solid concentration in the second stage was by a factor of two lower than that in the first stage. Its value has become comparable to the maximum value when the film flow exists, as has been determined experimentally as well as by calculation.

Table 2 shows the recovery of iron in the first and second stages of beneficiation by 6ERM-35/135 and DP-317 (Jones) separators during their comparative tests. Earlier, it was already shown [2] that the separator 6ERM-35/135 had higher recovery of iron than DP-317. It is shown here that DP-317 has lower recovery of iron in the second stage of beneficiation than in the first stage. This results from a decrease of particle size after they were milled from about $80 \%-75 \mu \mathrm{m}$ to about $95 \%-45 \mu \mathrm{m}$. Such a decrease of the recovery is natural for all types of separators. 
Table 2 Recovery (in \%, by operation) of iron by $6 \mathrm{ERM}-35 / 135$ and DP-317 magnetic separators

\begin{tabular}{|c|c|c|}
\hline Stage number & $6 \mathrm{ERM}-35 / 135$ & DP-317 \\
\hline First & 82.30 & 80.40 \\
\hline Second & 90.00 & 78.40 \\
\hline
\end{tabular}

On the contrary, the recovery of iron by $6 \mathrm{ERM}-35 / 135$ in the second stage is higher than that in the first stage. This results from the change of the hydrodynamics regime. In the first stage only part of the slurry moved in the form of a film. In the second stage, all the volume of the slurry flowed in the form of a film as a result of a decrease of the specific volumetric throughput.

Hydrodynamics of the other separator did not change in the second stage in spite of a decrease in the slurry volume, as it did not meet conditions for formation of the slurry film flow. Thus, this advantage of $6 \mathrm{ERM}-35 / 135$ magnetic separator is a consequence of the use of new hydrodynamics. Together with other improvements, it allowed to increase the efficiency and reliability of the rotary magnetic separator.

\section{REFERENCES}

[1] A.M. Turkenich and R.S. Ulubabov: Beneficiation of Minerals 5 , Technics, Kiev (1985)

[2] R.S. Ulubabov and A.M. Turkenich: Gorn. Zh. 5, Nedra, Moscow (1986)

[3] R.S. Ulubabov and V.I. Karmazin: Magn. Electr. Sep. 3 (1992), 77

[4] V.N. Poturaev et al.: Magnetic separator for beneficiation of weakly magnetic ores. Authors' Certificate 1015911 USSR (1981)

[5] L.G. Loytsanski: Mechanics of Liquids and Gases. Nauka, Moscow, 1973, p. 847

[6] A.M. Turkenich: VISTI (1985), 1713 
Alexander M. Turkenich graduated from the Dnepropetrovsk Mining Institute in 1960. In 1972 he obtained his Ph.D. degree for his work in high-gradient magnetic separation. In 1987 he obtained his senior doctorate D.Sc. Presently he is a laboratory head. His main field of interest is development of rotary magnetic magnetic separators 